\title{
A FERRUGEM ASIÁTICA DA SOJA CAUSADA POR Phakopsora pachyrhizi Sydow e Sydow
}

\author{
${ }^{\circ}$ Felipe Rafael Garcés Fiallos*,1 \\ *Bolsista da Secretaria Nacional de Educação Superior, Ciência, Tecnologia e Inovação de Equador - SENESCYT. \\ ${ }^{1}$ Unidad de Investigación Cientifica y Tecnológica, Universidad Técnica Estatal de Quevedo, $\mathrm{km} 7$ 1/2 vía Quevedo-El Empalme, \\ C.P.73. Mocache,Los Ríos, Ecuador. ${ }^{\triangleright}$ felipegarces23@yahoo.com
}

\begin{abstract}
Resumo
$\mathrm{O}$ Estados Unidos são o principal produtor mundial de soja, seguido pelo Brasil. A cultura da soja é afetada por 47 doenças já relatadas, entre elas a ferrugem asiática causada pelo fungo biotrófico Phakopsora pachyrhizi Sydow e Sydow. Esta doença pode atingir até $100 \%$ de dano e causa perdas no Brasil estimadas em 737,453,718 dólares ao ano. Em função de sua importância, faz-se oportuno uma revisão bibliográfica sobre esta doença, que abordará a sua ocorrência a nível mundial, a sintomatologia, os hospedeiros, a taxonomia e a etiologia do agente causal, efeitos dos fatores climáticos sobre a doença, ciclo biológico do patógeno, progresso e análise temporal, redução na área foliar e nos componentes de rendimento da cultura da soja e as estratégias de manejo integrado da enfermidade. Foi objetivo desta revisão recopilar as informações mais relevantes sobre a ferrugem asiática de modo o mais explicativo e entendível possível para o leitor.
\end{abstract}

Palavras chaves: Phakopsora pachyrhizi, Glycine max, urédias, lesões, estratégias de manejo integrado.
Abstract

$\mathrm{T}$ he united States is the world's largest producer of soybeans, followed by Brazil. The soybean crop is affected by 47 diseases previously reported, including soybean rust caused by the biotrophic fungus Phakopsora pachyrhizi Sydow e Sydow. This disease can reach $100 \%$ damage and losses may reach $737,453,718$ USD annually. Therefore a literature review of this disease becomes appropiate because it is very important to know about its occurrence worldwide, symptoms, hosts, taxonomy and etiologic of causal agent, effects of climatic factors over the disease, cycle of the pathogen, progress and temporal analysis of disease, reduced leaf area and yield components in soybean and control strategies disease integrated management, the aim of this review is to compile relevant information about soybean rust in the most explanatory and understandable way as possible for the reader.

Key words: Phakopsora pachyrhizi, Glycine max, biotrofic, uredia, injuries, strategies integrated management.

\section{INTRODUÇão}

A soja [Glycine $\max (\mathrm{L}$.$) Merrill] constitui uma das$ dez culturas de maior importância econômica a nível mundial por ser uma das principais fontes de concentrados protéicos e de óleo vegetal (Díaz et al., 1992). Os Estados Unidos são o principal produtor mundial de soja, seguido pelo Brasil. Na safra 20082009 a soja ocupou no Brasil, uma área entre 22,283 e 22,648 milhões de hectares, o que correspondeu a um aumento de 2.6 a 4.2\% em relação ao ano anterior. A produção total ficou entre 62.3 e 63.3 de milhões de toneladas, sendo um recorde nacional. Os principais estados produtores de soja são Mato Grosso, Paraná e Rio Grande do Sul (CONAB, 2009). No Equador a cultura da soja atinge as 54,350 hectares, concentrandose sua maior produção na província de Los Ríos (INEC, 2002).

Recibido: 23-Junio-2010. Recibido en forma corregida: 15-Agosto-2011. Aceptado: 7-Noviembre-2011.

Publicado como ARTíCULO DE REVISIÓN en Ciencia y Tecnología 4(2): 45-60. 2011
A cultura da soja é afetada por 47 doenças já relatadas, causando um prejuízo anual de um bilhão de dólares (Yorinori, 1997). Entre estas doenças estão às ferrugens, denominadas ferrugem americana e ferrugem asiática (Ono et al., 1992). A primeira é causada pelo fungo Phakopsora meibomiae e foi relatada pela primeira vez no Brasil em 1979, no estado de Minas Gerais (Deslandes, 1979) e Carvalho e Figuereido (2000) relatam que a espécie presente no Brasil até o ano 2000 era P. meibomiae. A ferrugem asiática tem como agente causal a espécie Phakopsora pachyrhizi Sydow e Sydow, sendo que Hartman et al. (1999) argumentam que $P$. pachyrhizi é mais agressiva que $P$. meibomiae.

A ferrugem asiática é considerada uma das doenças mais destrutivas e a que causa maiores danos em várias espécies de plantas da família Fabaceae, 
entre as quais se destaca a soja (Reis et al., 2006a). No Brasil, há relatos de $100 \%$ de dano, como no caso de um cultivo de safrinha em Chapadão do Sul, MS (Andrade e Andrade, 2002). Segundo Henning e Godoy (2006), as perdas na safra 2002-2003 atingiram 737,453,718.15 dólares. No Equador ainda não se conhece os danos e perdas reais que ocasionam na cultura.

Sendo esta uma doença muito destrutiva em todos os lugares onde a soja é cultivada, os conhecimentos sobre a mesma ainda são limitantes. Em função disso, apresentamos uma revisão bibliográfica desta doença que abordará os principais aspectos da doença dando subsídios para o manejo integrado da mesma.

\section{REVISÃo DE LITERATURA}

\section{Ocorrência}

A ferrugem asiática, causada pelo fungo $P$. pachyrhizi Sydow e Sydow, foi descrita pela primeira vez no Japão, em 1902 (Hennings, 1903), sendo que em 1914 já havia se disseminado para diversos países do sudeste de Ásia.

No continente africano foi registrada pela primeira vez em Togo em 1980 (Mawuena, 1982), depois em Uganda em 1996 (Kawuki et al., 2003), seguindo em 1998 no Kênia e Ruanda (Reis e Bresolin, 2004), Zimbábue e Zambia (Levy, 2005). Em 2001, foi encontrada na África do Sul e na Nigéria (Akinsanmi et al., 2001), atingindo caráter epidêmico (Pretorius et al., 2001). Em 2007, a ferrugem foi também relatada em Ghana (Bandyopadhyay et al., 2007).

No continente americano foi reportada pela primeira vez no ano 1976 em Porto Rico (Vakili e Bromfield, 1976), seguindo pelo Hawai em 1994 (Killgore e Heu, 1994). O primeiro relato na América do Sul ocorreu no Paraguai, em fevereiro de 2001 (Morel e Yorinori, 2002; Yorinori, et al. 2002a; Yorinori, et al. 2002b). No ano de 2002 a doença apareceu no Brasil (Yorinori, et al. 2002b; Costamilan, et al. 2002; Reis et al., 2002) e na Argentina (Rossi, 2003). Em 2003 foi relatada na Bolívia (Navarro et al., 2004) e na Colômbia (Reis et al., 2006a), progredindo em 2004 para o Uruguai (Stewart et al., 2005) e 2005 no Equador (SotomayorHerrera, 2005), México (Cárcamo-Rodríguez et al., 2006; Yáñez-Morales et al., 2009) e Estados Unidos (Schneider et al., 2005). Atualmente, a ferrugem asiática está presente em todos os países onde a soja é cultivada.

\section{Sintomatologia}

Os sintomas causados pela ferrugem asiática, no seu estado inicial, são facilmente confundidos com outras doenças, como pústula bacteriana (Xanthomonas axonopodes pv. glycines), crestamento bacteriano (Pseudomonas savastanoi pv. glycinea) e mancha parda (Septoria glycines). As frutificações não são muito evidentes, de modo que a olho nu se consegue distinguir pústulas ferruginosas, que conferem o nome comum a esse grupo de doenças (Reis et al., 2006a). O mesmo autor relata que os sintomas causados pela ferrugem da soja são denominados de "lesões", e não de pústulas, como as demais ferrugens, por que ocorre a necrose do tecido foliar e cada lesão pode apresentar varias pústulas (Figura 1).

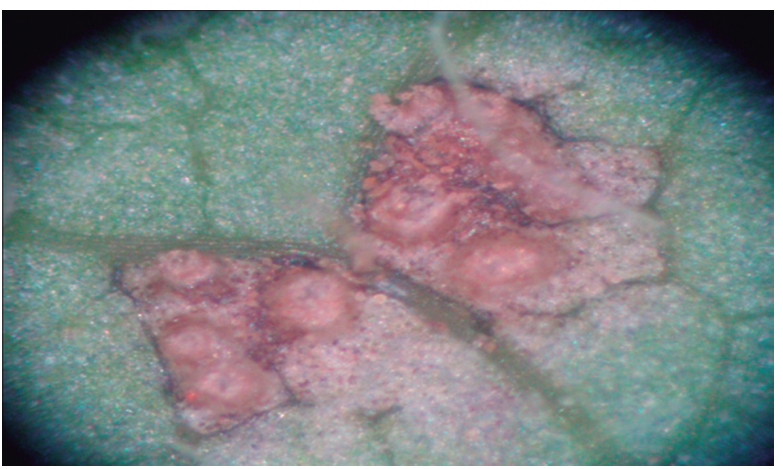

Figura 1. Duas lesões mostrando várias frutificações denominadas de pústulas ferruginosas.

Os sintomas (Figura 2) podem aparecer em qualquer estádio de desenvolvimento e em diferentes partes da planta, como cotilédones, folhas e hastes, sendo os sintomas foliares os mais característicos (Almeida et al., 2005). A cor das lesões varia do cinzaesverdeado ao marrom-avermelhado, com uma ou várias urédias globosas, principalmente na parte abaxial da folha (Hartman et al., 1999). Esporadicamente, as urédias podem aparecer na parte superior das mesmas (Almeida et al., 2005; Garcés, 2010).

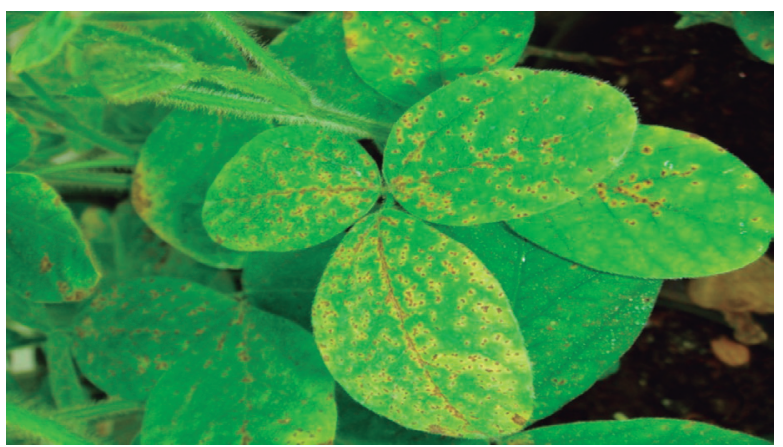

Figura 2. Sintomas da ferrugem asiática em trifólios de soja [Glycine $\max (\mathrm{L}$.) Merrill].

O número de lesões e urédias numa folha (parte abaxial) podem atingir até 26 e 46 por $\mathrm{cm}^{2} \mathrm{em}$ condições controladas, respectivamente (Garcés et al., 
2010b), ou 232 e 375 por $\mathrm{cm}^{2}$ a nível de campo (Garcés, 2010).

Segundo Garcés et al. (2010a) relata que 556 uredosporos são necessários para formar una urédia, entre tanto 909 uredosporos para originar uma lesão. Estes valores foram encontrados em trabalho realizado em laboratório procurando o umbral numérico de infecção da ferrugem asiática da soja.

A manifestação inicial da doença é observada como áreas foliares cloróticas de forma poligonal, por causa da delimitação imposta pelas nervuras, podendo atingir um tamanho de 2-5 $\mathrm{mm}^{2}$ (Reis et al., 2006a; Sinclair e Backman, 1993). As primeiras lesões, em geral, são encontradas nas folhas baixeiras próximas ao solo quando as plantas se encontram no estádio fenológico próximo ou após o florescimento (Reis et al., 2006a).

Progressivamente, as urédias, adquirem cor castanho-clara a castanho escuro, as quais se abrem em um minúsculo poro, expelindo os uredosporos, de coloração hialina que se tornam bege e se acumulam ao redor dos poros ou são removidos pelo vento (Almeida et al., 2005). À medida que prossegue a esporulação, o tecido da folha ao redor das primeiras urédias adquire coloração castanho-claro, denominada de lesão suscetível ou TAN (tanish) e a outra castanhoavermelhada, conhecida como lesão resistente ou RB (redish-brown) (Almeida et al., 2005; Bromfield e Hartwig, 1980; Kochman, 1977; Bonde et al., 2006; Miles et al., 2006).

O estádio final da epidemia da ferrugem da soja numa lavoura caracteriza-se por amarelecimento geral da folhagem com intensa desfolha, chegando até a queda completa das folhas (Reis et al., 2006a). Na figura 3 , observamos a sintomatologia progressiva da ferrugem asiática.

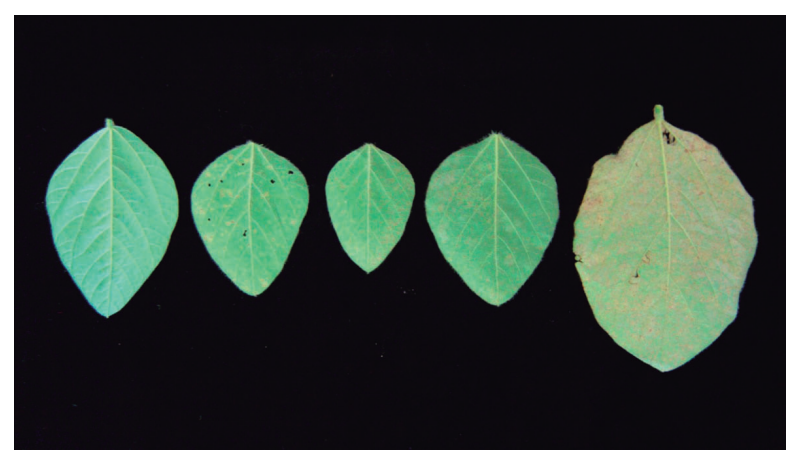

Figura 3. Sintomatologia progressiva da ferrugem asiática da soja, desde uma folha sem sintomas (A) até uma (quinta folha) com muitas lesões e pústulas ferruginosas.

\section{Hospedeiros}

O agente causal da ferrugem é um organismo biotrófico, o qual sobrevive em soja verde ou outros hospedeiros. Hartman et al. (1999) relatam que, ao contrário de outras ferrugens, P. pachyrhizi pode naturalmente infectar uma vasta gama de espécies vegetais, incluindo 41 espécies em 17 gêneros da família Fabaceae.Além disso, 60 espécies de plantas pertencentes a 26 gêneros foram infectados experimentalmente sob condições controladas (Rytter et al., 1984), podendo atingir até 90 espécies (Misman e Purwati, 1985). O fungo também pode infectar e esporular em espécies pertencentes à subfamília Papilionoideae, família Fabaceae, citando-se como principais hospedeiros as espécies Glycine max, G. sojae, Pachyrhizus erosus, Pueraria lobata e Vigna unguiculata (CABI, 2001). Na literatura são encontradas mais referências em relação aos hospedeiros de P. pachyrhizi, entre os quais se destacam os seguintes: Phaseolus vulgaris var. vulgaris, Canavalia gladiata (Poonpolgul e Surin, 1980; Stavely et al., 1985), Phaseolus vulgaris (Du Preez et al., 2005), Vicia faba, Vigna radiata, V. mungo, Psophocarpus tetragonolobus, Colopogonium muconoides (Poolpol e Pupipat, 1985), Alysicarpus vaginalis, Securigera varia, Melilotus officinalis, Trifolium repens, $T$. incarnatum, (Rytter et al., 1984), Phaseolus lunatus var. lunatus, Sesbania exaltata, Trigonella foenum-graicum (Bromfield, 1984), Phaseolus coccineus (Lynch et al., 2006), Pachyrhizus ahipa, Cajanus cajan (Yeh et al., 1981), Crotalaria anagyroides, C. spectabilis, Macroptilum atropurpureum (Keogh, 1974), Pueraria amontana var. lobata (Ono et al., 1992; Ivancovich, 2005), Lespedeza cuneata, Kummerowia striata, $K$. stipulaceae, Pisum sativum, (Sato e Sato, 1982), Lipinus albus, L. angustifolius, L. luteus, Lótus spp. (Keogh, 1974), dentre outras.

\section{Taxonomia}

Alexopoulos et al. (1996) indicam que o fungo que causa a ferrugem asiática da soja é classificado da seguinte maneira:

Reino:

Fungi

Classe: Basidiomycetes

Ordem: Uredinales

Família: Phakopsoraceae

Nome atual: Phakopsora pachyrhizi Sydow e Sydow

Sinônimos: Phakopsora sojae Fujikuro

Phakopsora calothea $\mathrm{H}$. Sydow

Malupa sojae (P. Hennings) Ono, Buritica, e Hennen comb. nov. (Anamorfo)

Uredo sojae P. Hennings 


\section{Etiologia}

A ferrugem da soja é ocasionada por duas espécies descritas. Uma denominada como ferrugem asiática ou australiana, causada por P. pachyhizi (forma anamórfica Malupa sojae), e a outra de ferrugem americana, causada por $P$. meibomiae (forma anamórfica M. vignae) (Hartman et al., 1999), sendo a primeira mais agressiva que a segunda (Agrios, 2005).

A fase teleomórfica de $P$. pachyrhizi apresenta teliosporos irregularmente distribuídos em camadas de 2 a 7 esporos; as paredes dos teliosporos variam do amarelo ao pardo-claro, mas também podem ser hialinos, tendo espessura de $1.0 \mu \mathrm{m}$ até $3.0 \mu \mathrm{m}$ nos esporos mais externos da camada (Hartman et al., 1999; Hennen e Reid, 2002; Reis et al., 2006a). Na fase anamórfica, os uredosporos (Figura 4) medem 15-24 x 18-34 $\mu \mathrm{m}$ e são ovóides, com paredes de $1.0 \mu \mathrm{m}$ de espessura e densamente equinulados, hialinos, amarelos ou marrom-claros. Segundo Littlefield e Schimming (1989), os uredosporos maduros quando molhados podem ser globosos ou ovalados e pedicelados. Para Sinclair e Backman (1993), os uredosporos podem ser expulsos em coluna através do poro central das uredias, estes, germinam dentro de 3-6 horas de incubação a 14$29^{\circ} \mathrm{C}$ (Hartman et al., 1999).

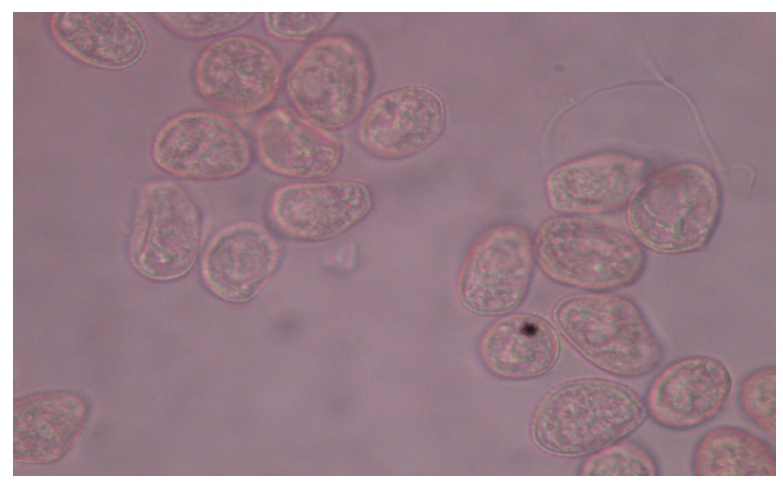

Figura 4. Uredosporos de Phakopsora pachyrhizi Sydow e Sydow $($ Bars $=10 \mu \mathrm{m})$.

\section{Efeitos dos fatores climáticos sobre a doença}

O principal objetivo da epidemiologia vegetal é entender os mecanismos que regulam o desenvolvimento das doenças. Numa cultura suscetível, o aumento da severidade da doença durante a estação de cultivo é determinado freqüentemente pelos fatores ambientais, principalmente temperatura e molhamento. Eles estão intrínsecos em muitos fatores que afetam o patossistema epidêmico, dentre os quais estão: ambiente (temperatura, duração de molhamento foliar e radiação), hospedeiro (idade da planta e da folha) e patógeno (idade dos uredosporos) (Alves et al., 2006).
A intensidade da ferrugem asiática da soja é diretamente influenciada pela freqüência de chuvas ao longo do ciclo da cultura (Galloti et al., 2006; Godoy et al., 2009).

O fungo $P$. pachyrhizi tem a capacidade de infectar uma planta de soja em temperaturas de 15 a $28^{\circ}$ C, com 6 a 12 horas de molhamento na superfície das folhas (Melching et al., 1989). Quanto à germinação dos uredosporos, foi demonstrado que o fungo é capaz de germinar entre as temperaturas de 7 e $28^{\circ} \mathrm{C}$, sendo a faixa ótima de 15 a $25^{\circ} \mathrm{C}$ (Marchetti et al., 1976). Por outro lado, Nicolini et al. (2010a) relata que podem germinar desde 5 até $30^{\circ} \mathrm{C}$, sendo a ótima $21^{\circ} \mathrm{C}$, demonstrando assim que os seres pecilotérmicos são regulados pela temperatura e não pelo tempo cronológico. Num experimento desenvolvido in vitro, por Carlini et al. (2009), a germinação máxima de uredosporos atingiu 96.5\% em placas de petri que continham $4.0 \mathrm{~g}$ de extrato de folha de soja-ágar. Segundo Melching et al. (1989), quando os uredosporos são analisados em meio ágarágua, não é observada a formação de apressório devido à consistência (mole) do meio de cultura.

Num trabalho conduzido na Austrália por Kochman (1979), o período latente foi de 14 dias numa faixa de temperatura variando de 7 a $17^{\circ} \mathrm{C}$, nove dias na faixa de 17 a $27^{\circ} \mathrm{C}$ e 11 dias na faixa de 22 a $32^{\circ} \mathrm{C}$. No Brasil, Reis et al., (2006a) relatam que P. pachyrhizi produz urédias 28 dias após a inoculação e que uma urédia individual pode produzir uredosporos durante 21 dias, paralisando o processo após 27 dias.

Em relação à formação de teliosporos por $P$. pachyrhizi, Dufresne et al. (1987) estudaram o efeito da temperatura e da intensidade de luz em dois isolados (Taiwan e Porto Rico), encontrando que o isolado proveniente de Taiwan produziu soros teliais aos 23 dias após a inoculação, enquanto que o isolado de Porto Rico produziu os teliosporos após 38 dias. As condições que induziram a formação de soros teliais foram baixa intensidade de luz $\left(3,9 \mu \mathrm{E} \mathrm{m}^{-2}\right)$ e temperatura de $10^{\circ} \mathrm{C}$. Em outro experimento, Sousa et al. (2006) relatam que a presença de soros teliais teve início aos 15 dias a $15^{\circ}$ C. É importante assinalar que a formação de teliosporos é rara na maioria dos hospedeiros nas regiões tropicais, pois não há condições favoráveis como a umidade e a temperatura (Yeh et al., 1981).

Bonde et al. (1976), Koch et al. (1983) e Zambenedetti et al. (2007a) relatam que P. pachyrhizi, ao contrário de outras ferrugens, apresenta penetração direta sobre a cutícula com a formação de apressório.

Isard et al. (2006) estudaram o efeito da radiação solar expressado em megajaules metro ${ }^{-1}$ quadrado $\left(\mathrm{MJ} \mathrm{m}^{-2}\right)$ sobre a mortalidade de P. pachyrhizi, onde acharam que uredosporos expostos a radiação solar de $\geq 27.3 \mathrm{MJ} \mathrm{m}^{-2}$ não germinam. Os mesmos autores geraram uma equação linear relacionando a variável X (radiação solar dada em 
MJ m ${ }^{-2}$ ) com a variável Y (germinação de uredosporos de $P$. pachyrhizi expostos), resultando $\mathrm{Y}=-0.0307 \mathrm{X}$ +1.0084 . No Brasil, Nicolini et al. (2010b) relata que o tempo de exposição a radiação solar de cinco horas não ocorreu germinação de uredosporos, sendo que a medida que o tempo de exposição aumentou, a taxa de germinação dos uredosporos diminuiu, concluindo assim que a radiação solar interfere negativamente na germinação de uredosporos da ferrugem asiática.

Zambenedetti et al. (2007a) relatam que o período de incubação foi de seis dias para todos os sete genótipos avaliados. Entretanto, o período latente variou de seis a doze dias.

Para estudos epidemiológicos da ferrugem da soja, tem sido desenvolvido ao longo dos anos sistemas ou modelos que simulam e mostram o comportamento do fungo no tempo e no espaço, sejam em condições controladas ou no campo. Por exemplo, Yang et al. (1991a) produziram uma série de modelos empíricos que relacionam produção com área baixo a curva de progresso da doença (AACPD). Posteriormente, Yang et al. (1992), usando duração de área foliar sadia (HAD) como variável independente, conseguiram resultados sensivelmente superiores ao do trabalho anterior. Algo diferente foi proposto por Kim et al. (2005), que utilizaram variáveis biológicas e meteorológicas para predizer o progresso da doença antes mesmo da infecção pelo patógeno. Também Pivonia e Yang (2006) criaram um modelo geral baseado na relação do ambiente e diferentes condições do desenvolvimento da ferrugem da soja (período de latência) em diferentes tempos em regiões importantes produtoras de grãos nos Estados Unidos (Baton Rouge, LA, Charlotte, NC; Indianapolis, IN; Minneapolis, MN.).

Igualmente, vem sendo gerados modelos climáticos de previsão da ferrugem da soja. Reis et al. (2004) elaboraram um sistema de previsão da ferrugem da soja tomando como base dados disponíveis na literatura. O modelo baseia-se nas condições climáticas favoráveis ao processo infeccioso, como a duração de molhamento foliar contínuo e a temperatura média durante essa subfase do ciclo das relações patógeno-hospedeiro, tendo assim como resultado uma equação que mostra a interação desses dois fatores sobre a intensidade de P. pachyrhizi (número de lesões por $\mathrm{cm}^{2}$ ). Del Ponte et al. (2006), utilizando dados de março de 2003 a maio de 2004 de 34 experimentos de campo de 21 locais do Brasil, geraram quatro modelos lineares. Esse estudo coloca a importância das precipitações pluviais para influir nas epidemias da ferrugem da soja no Brasil, assim como seu uso potencial para proporcionar previsões de risco quantitativo em regiões onde a temperatura não é um fator limitante para o desenvolvimento da doença. Por outro lado, Pan et al. (2006) estudaram a dispersão dos esporos de $P$. pachyrhizi e geraram um modelo integrado entre o transporte dos propágulos e o clima da região. O modelo prediz a trajetória e a concentração de esporos, informação que pode ser muito útil na previsão da doença.

\section{Ciclo biológico do patógeno e da doença}

Segundo Alexopoulos et al. (1996), de forma geral, as ferrugens podem produzir cinco estágios diferentes em seu ciclo de vida, sendo eles: estágio 0 (espermogônios produtores de espermácias e hifas receptivas), estágio 1 (aécia produzindo aéciosporos), estágio 2 (uredia produzindo urediniosporos), estágio 3 (télia produzindo teliosporos) e estágio 4 (basídias produzindo basidiosporos).

$\mathrm{O}$ agente causal da ferrugem da soja, o fungo $P$. pachyrhizi é um parasita biotrófico ou também denominado de parasita obrigatório. Segundo Reis et al. (2006a), biotrófico é aquele parasita que depende nutricionalmente dos tecidos vivos do hospedeiro, ou seja, da célula viva, de onde extraem os nutrientes essenciais a suas atividades vitais, apresentando assim menor número de oportunidades ou mecanismos para sobrevivência do que os necrotróficos.

Reis et al. (2006a), Park et al. (2008) e Slaminko et al. (2008) indicam que uredosporos de $P$. pachyrhizi podem sobreviver no inverno de uma safra para outra em plantas de kudzú (Pueraria lobata), as quais servem de fonte de inóculo. Os esporos secos do fungo são disseminados pelo vento (Maude, 1996) ou por outros meios, como pessoas (Hartman e Haudenshield, 2009).

Para que ocorra a germinação, o fungo precisa de molhamento (água livre ou orvalho) e temperatura favorável. Marchetti et al. (1976) chegaram à conclusão que a melhor temperatura para o desenvolvimento da doença é entre 15 e $25^{\circ} \mathrm{C}$, enquanto Kochman (1979) relata que a temperatura ótima para a germinação é de $21-27^{\circ} \mathrm{C}$.

Bonde et al. (1976) e Koch et al. (1983) argumentam que a penetração ocorre seis horas após a deposição, diretamente através da cutícula. Zambenedetti et al. (2007a) observaram a formação de apressório entre quatro a seis horas após inoculação. $\mathrm{O}$ período latente pode durar 14 dias em temperaturas de 7 a $17^{\circ} \mathrm{C}$, nove dias no regime de 17 a $27^{\circ} \mathrm{C}$ e 11 dias no de 22 a $32^{\circ} \mathrm{C}$ (Kochman, 1979).

A formação de lesões angulares se dá em função do crescimento das hifas serem restritas às nervuras da folha (Reis et al., 2006a). A formação das urédias se dá por uma agregação de hifas, formando o primórdio uredial (Zambenedetti, 2005).

Para melhor esclarecimento do ciclo biológico da doença, pode-se observar a figura 5 . 


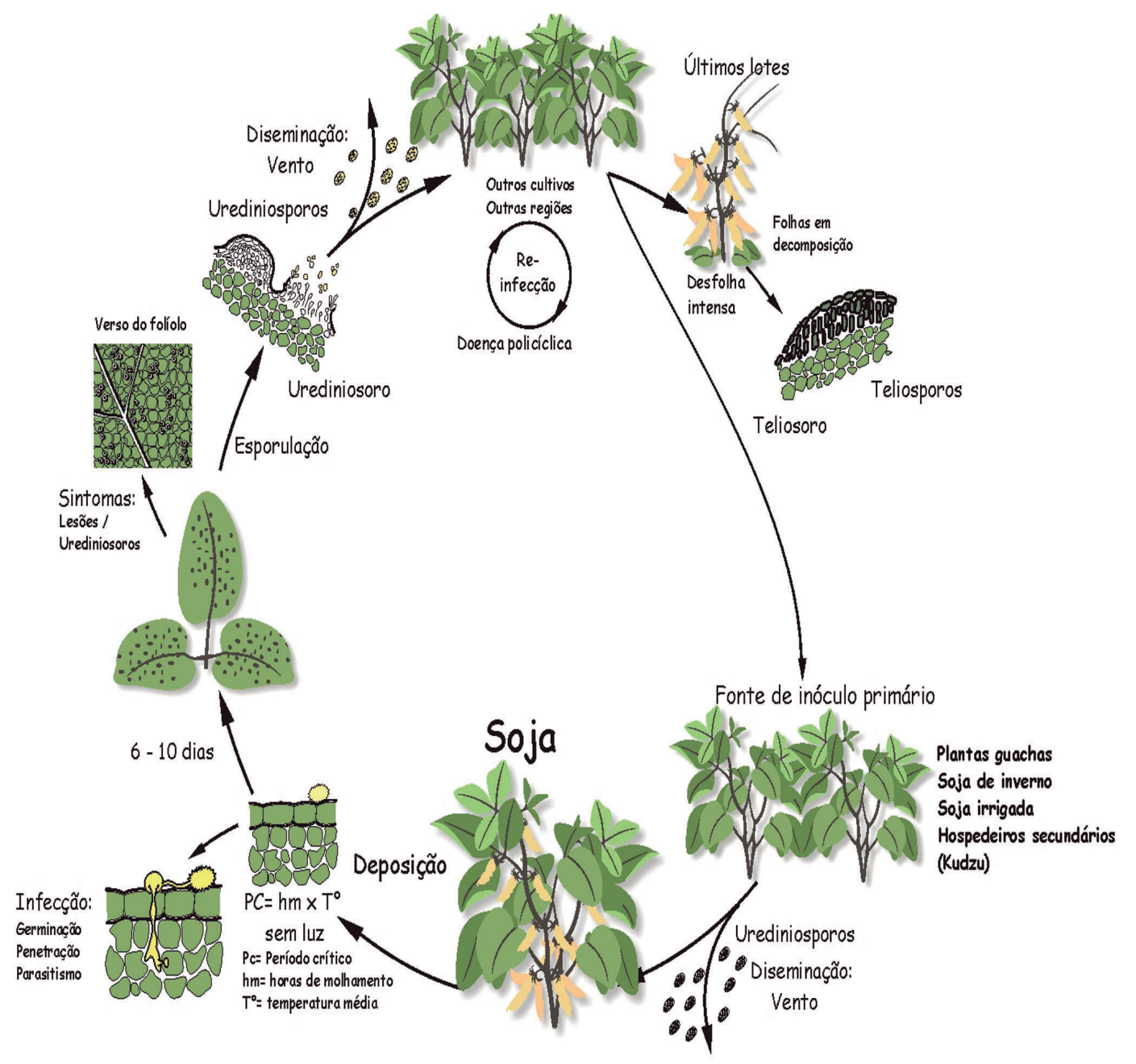

\section{Ciclo da ferrugem da soja}

(Phakopsora pachyrhizi)

Fonte : E.M. REIS - M.A. CARMONA

Figura 5. Ciclo biológico da ferrugem asiática da soja causada por Phakopsora pachyrhizi (Reis e Carmona, 2005 citado por Reis et al., 2006a).

\section{Progresso e análise temporal da doença}

Os modelos matemáticos são uma das poucas ferramentas disponíveis para se comparar epidemias e distinguir variedades, tratamentos com fungicidas, técnicas de manejo, bem como gerar modelos de previsão e auxiliar na quantificação de danos e perdas (Bergamin Filho, 1995). Para o estudo do progresso de doenças, têm-se usado principalmente modelos empíricos, dentre os quais: Exponencial, Logístico, Gompertz e Monomolecular, e modelos flexíveis como o de Weibull (Jesus et al., 2004). Também são citados os modelos de Richards, o dependente do tempo e o sigmóide duplo (Bergamin Filho e Amorim, 1996). Deve-se mencionar que existem poucos trabalhos a nível mundial e no Brasil sobre o progresso e análise temporal da ferrugem da soja até a presente data, utilizando os modelos empíricos mencionados anteriormente.

Nos Estados Unidos, Kim et al. (2005) visando prever a taxa da infecção aparente de $P$. pachyrhizi antes de que aconteça mediante a combinação das variáveis meteorológicas e biológicas em duas cultivares: TK 5 e G 8587, geraram uma curva de progresso do modelo logístico para a melhor representação da epidemia causada pela ferrugem, tendo como resultante taxas de infecção aparente de $\left(\mathrm{r}^{2}\right) \quad 0.1,0.15$ e 0.2 .

$\mathrm{Na}$ Argentina, foi estudado o progresso da ferrugem da soja utilizando dados de severidade (urédias folíolos ${ }^{-1}$ ) e incidência em três safras (20042005, 2005-2006 e 2006-2007) na Estação do INTA no Departamento do Paraná, para o qual foi utilizado o modelo logístico para incidência e exponencial para severidade, obtendo taxas de progresso entre 0.05 e 0.87 (Souza e Formento, 2008). 
Já no Brasil, Gastaldi (2005) explicou o progresso da ferrugem com um modelo logístico com dados de severidade da ferrugem da soja. Em função do melhor ajuste, utilizou-se para o cálculo da taxa aparente de infecção a equação $\mathrm{r}=(1 / \mathrm{t}) *(\ln (\mathrm{x} /(1-$ $\left.\mathrm{x}))-\ln \left(\mathrm{x}_{0} /\left(1-\mathrm{x}_{0}\right)\right)\right)$. Da mesma forma, Tsukahara et al. (2008) explicou o desenvolvimento da ferrugem com um modelo logístico, pois foi também o que melhor se ajustou aos dados de severidade da doença para os dois locais testados, com coeficiente de determinação $\left(\mathrm{R}^{2}\right)$ igual a 0.95 (Arapoti) e 0.98 (Castro). Por outro lado em Campo Verde, MT, Blum et al. (2004) avaliou e explicou o progresso da doença em relação ao número de lesões $\mathrm{cm}^{-2}$ com um modelo linear simples, achando um incremento diário de 0.8867 de lesões $\mathrm{cm}^{-2}$. Para a incidência medida em folíolos foi explicado melo modelo Monomolecular não linear, obtendo a equação $\mathrm{IF}=1-(1-0.001)$ EXP $(-0.098 \mathrm{t})$ com $\mathrm{R}^{2} 0.96$, onde IF é a incidência em folíolos e t o tempo. Já em Passo Fundo, RS, a taxa diária da ferrugem asiática foi de 0.3263 unidades ao dia, atingindo em 22 dias 96\% de incidência (Reis et al., 2006b). Entretanto, Garcés (2010) na mesma região, estudando o progresso da doença em função da incidência e severidade nos estratos inferior, médio e superior, e meio da planta, encontraram taxas de progresso parecidas $(0.13 ; 0.14$; 0.13 e 0.06$)$ no modelo Logístico e $(0.10 ; 0.10 ; 0.11$ e 0.4) no de Gompertz (Tabela 1). Avozani et al. (2010) no mesmo local acharam taxas de 3.96 e 3.80 unidades ao dia nas cultivares Apolo RR e Fundacep 55 RR, respectivamente, com base na incidência da ferrugem.

Tabela 1. Quantidade inicial (Y0), taxa de progresso da ferrugem asiática (r) estimados pelos modelos Logístico e de Gompertz, coeficiente de determinação $\left(R^{2}\right)$ e quadrado médio do resíduo (QMR), obtidos nos respectivos modelos para a severidade (\%) em proporções de plantas de soja, cultivar Nidera 5909 RG. Passo Fundo, RS, safra 2009-2010

\begin{tabular}{lcccccccc}
\hline \multirow{2}{*}{ Estratos } & \multicolumn{4}{c}{ Logístico } & \multicolumn{3}{c}{ Gompertz } \\
\cline { 2 - 9 } & $\mathbf{Y}_{\mathbf{0}}$ & $\boldsymbol{r}$ & $\mathbf{R}^{\mathbf{2}}$ & $\mathbf{Q M R}$ & $\mathbf{Y}_{\mathbf{0}}$ & $\boldsymbol{r}$ & $\mathbf{R}^{\mathbf{2}}$ & $\mathbf{Q M R}^{\mathrm{N}}$ \\
\hline Inferior & 205.2 & 0.13 & 0.92 & 0.2539 & 4.60 & 0.10 & 0.93 & 0.2651 \\
Médio & 279.4 & 0.14 & 0.95 & 0.2889 & 4.75 & 0.10 & 0.96 & 0.2848 \\
Superior & 598.8 & 0.13 & 0.88 & 0.6647 & 5.95 & 0.11 & 0.88 & 0.6641 \\
\hline Média & 15.76 & 0.06 & 0.99 & 0.0202 & 2.64 & 0.04 & 0.98 & 0.0325 \\
\hline
\end{tabular}

Redução na área foliar e nos componentes do rendimento na cultura da soja

Na abordagem na análise do dano por doenças envolve sua relação com a área foliar da planta, e desta com o rendimento de grãos. Van der plank (1963) menciona que para avaliar os efeitos proporcionados pelo controle químico, relaciona-se produção com área foliar doente (severidade) ou área foliar removida (desfolha). Na quantificação de produção, a variável mais relevante do crescimento do hospedeiro é a área foliar total por unidade de área de terreno, essa variável é conhecida como índice de área foliar (IAF) (Bergamin Filho e Amorim, 1996). A perda de área foliar causadas pelas doenças afeta a interceptação de luz, a capacidade fotossintética, o acúmulo de fotossintatos e o período do enchimento de grãos (Board et al., 1994). Agrios (2005) menciona que a ferrugem apresenta lesões e urédias nos dois lados da folha e reduz significativamente a habilidade de realizar a fotossínteses, produzindo assim grandes danos na cultura da soja.

Na literatura encontra-se muitos trabalhos onde foram estudados a variável IAF, com o patossistema
soja-P. pachyrhizi (Yang 1991b; 1992; Garcés, 2010) entre outros. Garcés (2010) comprovou que a ferrugem asiática é a importante causa de desfolha na cultura da soja, quanto maior a quantidade de ferrugem, maior o número de urédias por unidade de área, portanto, maior interferência no metabolismo da folha e maior a perda de água, com reflexo na durabilidade dos.

Bromfield (1984) menciona que a ferrugem asiática da soja pode causar decréscimo no enchimento de vagens por planta, número normal de vagens por planta, número de sementes por planta, peso de sementes por planta e de 1,000 sementes. No entanto, Garcés (2010) relata que os componentes do rendimento de grãos, avaliados com número de vagens e grãos por planta, assim como grãos por vagem, não variaram significativamente entre os diversos tratamentos, apesar das diferenças numéricas, embora tenha grande variação entre blocos e unidades experimentais, resultando em coeficientes de variação elevados. Por outro lado, na análise entre os estratos da planta, os componentes do rendimento foram muito similares entre si nas partes média e superior. 


\section{Estratégias de manejo integrado}

A ferrugem da soja é uma doença destrutiva em todos os países onde foi detectada, e tem sido alvo de exaustivo controle. Embora na literatura encontramse muitos trabalhos de controle químico, existem outros tipos de controle como cultural, genético e alternativo, sendo também alvos de estudo.

\section{Controle cultural}

Uma das indicações de controle cultural é aumentar a área de rotação de culturas, pois onde se pratica essa medida por um ano, com gramíneas como milho, sorgo e arroz, no lugar da soja safrinha, tem facilitado o controle da ferrugem (Yorinori, 2004; Zambolin, 2006), pois favorece o manejo de plantas voluntárias.

O principal mecanismo de sobrevivência de fungos biotróficos, como $P$. pachyrhizi, é o parasitismo de plantas vivas no período em que o hospedeiro principal não está sendo cultivado. Reis et al. (2006a) relatam que as plantas de soja que se desenvolvem espontaneamente nas lavouras, como resultado da perda de grãos na colheita, aumentam o período da presença de soja-verde, garantindo a sobrevivência parasitária de $P$. pachyrhizi por período determinado, razão pela qual a população destas plantas deveria ser reduzida ou eliminada. Outra fonte de inóculo são os hospedeiros secundários. No Rio Grande do Sul, Brasil, o kudzú é um dos principais (Reis et al., 2005).

Também é necessário fazer um manejo da irrigação por aspersão, a fim de reduzir o molhamento foliar que favorece a germinação dos esporos e a penetração do fungo na planta (Reis et al., 2006a).

A utilização de cultivares de ciclo precoce diminui o tempo de exposição da planta ao patógeno, da mesma forma a realização da semeadura em épocas preferências, evitando-se semeaduras tardias (Reis et al., 2006a), pois a carga de inóculo é maior em função da multiplicação do fungo nos primeiros cultivos (Yorinori, 2004).

O arranjo populacional das plantas também pode contribuir para atenuar a ferrugem. Ferreira (2009) e Ramos et al. (2009) observaram que maior espaçamento entre linhas de cultivo resulta em menor severidade da ferrugem e também permite melhor distribuição do fungicida durante a aplicação, facilitando o manejo da doença. Se a densidade da semeadura for alta em espaçamentos densos, haverá dificuldade de penetração da calda e, conseqüentemente poderá haver cobertura deficiente das folhas no dossel, sendo assim o controle da doença deficiente, mesmo adotando-se fungicida eficiente (Zambolin, 2006).

\section{Controle genético (resistência de cultivares)}

Tem sido difícil encontrar materiais resistentes às ferrugens, pois como descreve Van der Plank (1968) os poucos materiais catalogados como resistentes, tem resistência vertical ou monogênica, carecendo de resistência horizontal ou poligênica, devido à variabilidade das ferrugens. Não se dispondo de cultivares resistentes indicadas comercialmente, tornase o controle químico a alternativa mais eficaz no controle da doença (Navarini et al., 2007). No entanto, a utilização de resistência à ferrugem da soja é uma das estratégias mais eficazes a longo prazo para controlar a doença (Shuxian, 2010).

Cinco das principais fontes de resistência à ferrugem asiática foram identificadas em soja: Rpp1 (Cheng e Chan, 1968; Mclean e Byth, 1980; Hartwig e Bromfield, 1983), Rpp2 (Hidayat e Somaatmadja, 1977), Rpp3 (Bromfield e Hartwig, 1980; Van de Mortel, et al., 2007), Rpp4 (Hartwig, 1986) e Rpp5 (Garcia et al., 2008). Juntas, as análises genéticas e moleculares sugerem vários alelos ou genes estreitamente ligados que governam a resistência a ferrugem da soja (Garcia et al., 2008).

Zambenedetti et al. (2007b) estudando os genótipos PI 230970 e PI 459025 apresentaram baixa porcentagem de urediniósporos germinados e de formação de apressórios. Nestes genótipos a formação de apressório começou seis horas após a inoculação, enquanto que, nos demais cultivares ocorreram quatro horas após a inoculação. Estes genótipos podem apresentar genes de resistência Rpp2 e Rpp4, respectivamente (Hartwig e Bromfield, 1983; Hartwig, 1986). Outra pesquisa realizada por Pham et al. (2009) encontrou que quando cada uma das fontes de resistência conhecidas (Rpp1 a Rpp4) foi avaliada com três isolados da ferrugem asiática, os cultivares PI200492 (Rpp1) e PI462312 (Rpp3), produziram uma resposta diferencial enquanto PI230970 (Rpp2) e PI459025B (Rpp4) produziu lesões suscetíveis. Koga et al. (2008) avaliando os componentes da resistência a ferrugem asiática em 48 cultivares de soja, selecionaram alguns grupos de genótipos que podem ser considerados promissores como fontes de genes de resistência à doença.

Recentemente foi realizada uma análise da reação de vários genótipos de soja a três populações de ferrugem asiática, uma proveniente de Japão e duas do Brasil, encontrando apenas dois genes de resistência, sendo eles Rpp4 presente na variedade PI459025 e Rpp5 na variedade Shiranui que conferiram resistência a três populações do fungo (Yamanaka et al., 2010).

No Brasil, para a safra 2009-2010 foi disponibilizado aos agricultores em algumas regiões 
brasileiras os cultivares de soja TMG $801-\mathrm{INOX}{ }^{\circledR}$ e TMG 803- INOX ${ }^{\circledR}$ com resistência a ferrugem asiática (FUNDAÇÃO MT, 2009). No Equador ainda não existem genótipos resistentes à doença.

\section{Controle alternativo}

Existem muitos trabalhos realizados sobre esta modalidade, mas na sua maioria in vitro, onde mostram resultados satisfatórios como exemplo aqueles relatados por Medice (2007), utilizando óleos essenciais de eucalipto citriodora (Corymbia citriodora), citronela (Cymbopogon nardus), nim (Azadirachta indica) e tomilho (Thymus vulgaris L). Todos esses óleos reduziram drasticamente a germinação de urédiosporos. Também Maciel, et al. (2009) empregando extratos aquosos de tiririca (Cyperus rotundus) obtidos por infusão, obtiveram inibições de até $14 \%$ na germinação de esporos. Medice (2007) realizando um experimento in vivo, relata que o óleo de tomilho (Thymus vulgaris L) agiu sobre a germinação de urédiosporos na folha, na formação de urédias e sobre a viabilidade dos urédiosporos, reduzindo a doença em até $69.59 \%$.

\section{Controle químico}

Com o aparecimento da ferrugem asiática, o uso de fungicidas na cultura da soja aumentou, sendo até a presente data a ferramenta, mas importante para controlar o fungo e evitar reduções na produtividade danos na produção e perdas ao produtor.

Informações sobre a eficiência de fungicidas para controle das diferentes doenças são cada vez mais necessárias para orientar a sua correta utilização no campo (Godoy et al., 2007).

Segundo o MAPA (2009), os fungicidas registrados para o controle da ferrugem asiática da soja no país, até hoje, em pulverização na parte aérea da cultura, isolados e/ou em mistura são os seguintes: azoxistrobina, ciproconazol, difenoconazol, epoxiconazol, fluquinconazol, flutriafol, metconazol, miclobutanil, picoxistrobina, propiconazol, protioconazol, tebuconazol, tetraconazol, azoxistrobina+ciproconazol, carbendazim+flutriafol, ciproconazol+picoxistrobina, ciproconazol+propiconazol, ciproconazol+trifloxistrobina, epoxiconazol+piraclostrobina, flutriafol+tiofanato metílico, propiconazol+trifloxistrobina e tebuconazol+trifloxistrobina, totalizando 54 formulações comerciais. Para o tratamento de sementes encontra-se registrado o princípio ativo fluquinconazol, em apenas uma formulação comercial.

Dentre os critérios para o uso de fungicidas por vários anos foram ajustados procurando-se a melhor resposta de controle quando a soja encontrava-se entre florescimento, formação de legume e início e meio da granação. Até hoje se discute critérios para iniciar seu controle: preventivo, primeiros sintomas, 5\% de incidência foliar, estádio de desenvolvimento (que vario muito entre indicações e opinião de pesquisadores nestes poucos anos de ocorrência da doença), no préfechamento das linhas de semeadura, com base em parcelas armadilhas, considerando clima e prevendo clima e infecção (Deuner et al., 2009).

Hartman et al. (1991) relatam que fungicidas aplicados de forma preventiva tem se destacado como estratégia mais eficaz no controle desta doença. Estudos realizados mostram também que, em condições severas de epidemia, são necessárias de três a cinco aplicações em intervalos de 10 dias (Sinclair e Hartman, 1995). Já (Levy, 2005) com relação a momento de aplicação, conduzindo ensaios na África, mostraram que três ou mais aplicações foram necessárias para manter o potencial produtivo, enquanto que uma ou duas aplicações foram insuficientes para controlar a doença.

A ocorrência de uma doença na fase vegetativa da soja e a necessidade de melhor distribuição do fungicida nas partes inferiores da planta levam a aplicações de fungicidas antes da fase reprodutiva (Almeida et al., 2009b). Em cultivares com maior carga de vagens e grãos no terço inferior, aplicações de fungicidas nos estádios vegetativos otimizam o controle de doenças e potencializam o rendimento de grãos (Almeida et al., 2009a).

Também tem que ter em conta que a eficiência de um tratamento depende não somente da quantidade do material depositado sobre a vegetação, mas também da uniformidade do alvo, sendo de maneira geral, a deposição menor nas partes baixas e internas do dossel das culturas (Cunha et al., 2006).

Alem da discrepância sobre o momento de aplicação dos fungicidas, ultimamente vem-se apregoando a aceitação da sensibilidade de fungicidas, no caso específico do tebuconazol a $P$. pachyrhizi. Em relação a esse tema, existem poucas referências indicando este fato, seja por tabu ou por afirmar essa ocorrência de maneira científica. Para isto Alvim et al. (2009a, 2009b) e Garcés (2010) relatam que o fungicida tebuconazol pertencente ao grupo dos triazóis, aplicado de forma isolada apresentou menor eficácia no controle da ferrugem da soja, podendo ser atribuído a redução na sensibilidade do fungo ao fungicida. Já Garcés (2010) relata que aplicações realizadas antes do fechamento do espaço entre linhas de cultivo resultam em melhor controle, pois permitem distribuir o fungicida na parte inferior da planta, além de atingir a doença no seu início. O mesmo autor relata que a mistura de triazol + estrobilurina é mais efetiva que o triazol sozinho no controle da ferrugem asiática (Figura 6). A eficácia 


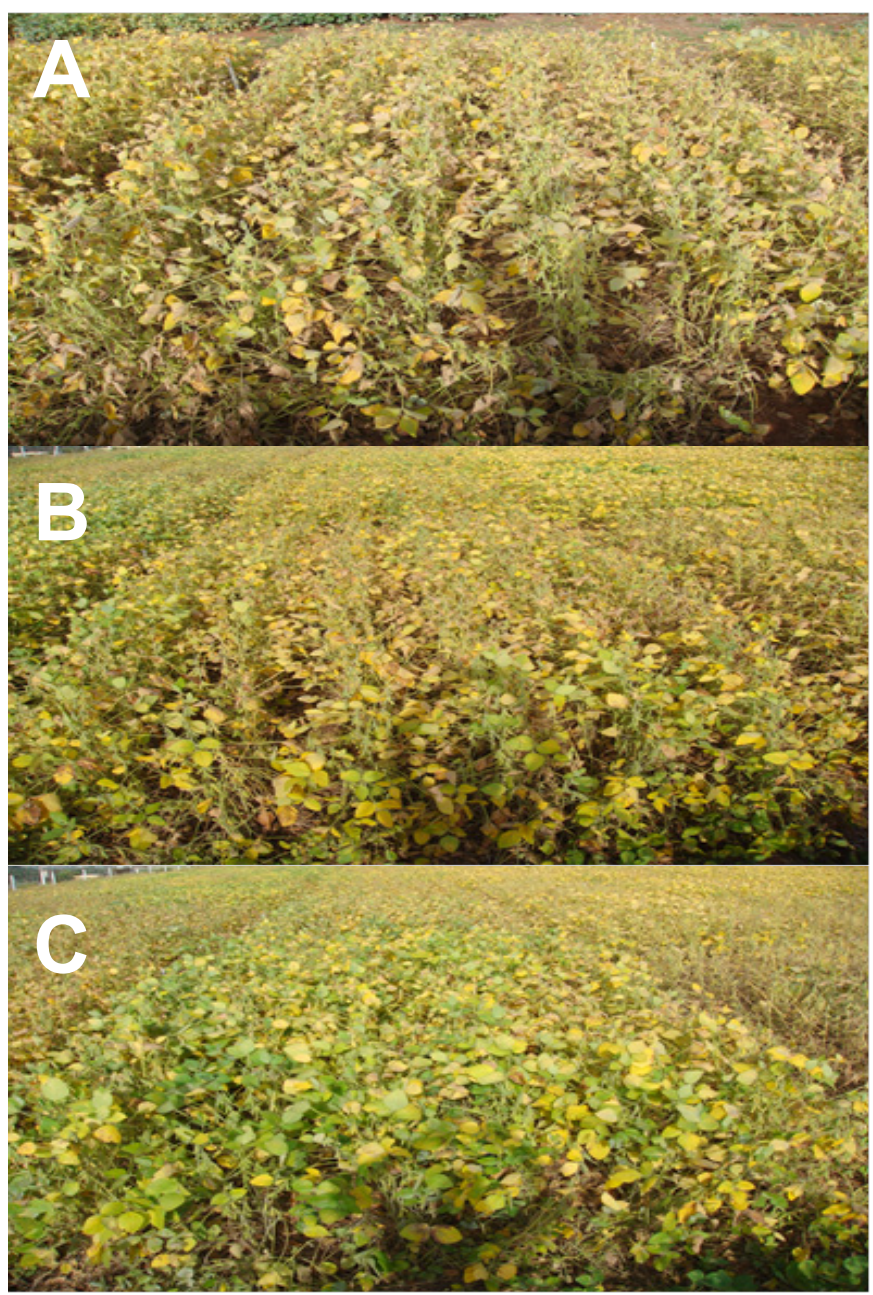

Figura 6. Tratamentos de soja: sem aplicação de fungicida (A), aplicado somente triazol (B) e uma mistura de triazol + estrobirulina (C) (Garcés, 2010).

destes grupos químicos em controlar a ferrugem asiática da soja é corroborado por Godoy e Canteri (2004), Godoy et al. (2007), Scherm et al. (2009) e Viero (2008).

O monitoramento da intensidade da doença no campo juntamente com as condições climáticas (temperatura, umidade relativa, horas de molhamento foliar, precipitação pluviométrica, vento e outros fatores) são fundamentais no manejo integrado de doenças (MID) de plantas (Zambolim et al, 2007). O mesmo autor menciona que a ferrugem asiática apresenta provável surgimento de resistência cruzada entre fungicidas. Este fato faz que se torne mais importante ainda o manejo da doença de forma integrada, utilizando todas ou a maioria das técnicas estipuladas neste artigo, obtendo assim uma baixa intensidade da doença e maior área foliar nas plantas de soja em uma lavoura, assim como altos rendimentos $\left(\mathrm{kg} \mathrm{ha}^{-1}\right)$ e excelente produtividade para o produtor.

\section{Agradecimientos}

A Secretaria Nacional de Educação Superior, Ciência, Tecnologia e Inovação do Equador SENESCYT pela bolsa concedida ao primeiro autor para estudos de Maestria em Agronomia com Área em Fitopatologia na Universidade de Passo Fundo, RS, Brasil.

\section{Literatura CITADA}

Agrios, G. N. 2005. Plant Pathology (5th Ed.). Amsterdam, Elsevier Academic Press.

Akinsanmi, O. A., J. L. Ladipo, P. O., and Oyekan, 2001. First report of soybean rust (Phakopsora pachyrhizi) in Nigeria. Plant Disease 85(1):97.

Alexopoulos, G. J., C. W. Mims and M. Blackwell. 1996. Introductory Mycology (4th Ed.). New York, Jhon Wiley e Sons. 
Almeida, A. M. R., L. P. Ferreira, J. T. Yorinori, J. F. V. Silva, A. A. Henning, C. V. Godoy, L. M. Costamilan, e M. C. Meyer. 2005. Doenças de soja. Em: Kimati, H., L. Amorim,J. A. M. Rezende, A. Bergamin Filho e L. E. A. Camargo (Eds.) Manual de Fitopatologia. Vol. 2 (4ta Ed.). Piracicaba, Livroceres. p. 376-399

Almeida R., C. A. Forcelini, e F. R. Garcés. 2009a. Análise de distribuição dos componentes de rendimento na planta como critério para a época de aplicação de fungicidas em soja. Tropical Plant Pathology 34 (Suplemento): S79 (Resumo).

Almeida R., C. A. Forcelini, e F. R. Garcés. 2009 b. Controle de doenças em soja através de aplicações antecipadas de fungicida. Tropical Plant Pathology 34 (Suplemento): S79 (Resumo).

Alves, S. A. M., G. Q. Furtado, e A. Bergamin Filho. 2006. Influência das condições climáticas sobre a ferrugem da soja. Em: Zambolim, L. (Org.). Ferrugem Asiática da Soja. Visconde do Rio Branco, MG, Suprema Gráfica e Editora. p. 37-59.

Alvim Jr., M, G., F. C. Juliatti, M. S. Alvim, F. O. S. Parreira, P. S. Silva, B. C. M. Juliatti, A. A. Rezende, J. A. S. Martins, e E. Sagata. 2009a. Avaliação de fungicidas registrados no MAPA no controle da ferrugem da soja. Tropical Plant Pathology 34 (Suplemento): S84 (Resumo).

Alvim, M, S., F. C. Juliatti, M. G. Alvim Jr., F. O. S. Parreira, P. S. Silva, B. C. M. Juliatti, A. A. Rezende, e E. Sagata 2009b. Novos fungicidas no controle da ferrugem na cultura da soja. Tropical Plant Pathology 34 (Suplemento): S98 (Resumo).

Andrade, P. J. M., e Andrade, D. F. A. 2002. Ferrugem asiática: uma ameaça a sojicultura brasileira. Dourados, EMBRAPA. (Circular técnica, 11).

Avozani, A., E. M. Reis, A. L. D. Danelli, R. B. Tonin, F. Nicolini, e F. R. Garcés. 2010. Progresso da ferrugem da soja na safra 2009/10 em Passo Fundo/ RS. Tropical Plant Pathology 34 (Suplemento): S139 (Resumo).

Bandyopadhyay, R., P. S. Ojiambo, M. Twizeyimana, B. Asafo-Adjei, R. D. Frederick, K. F. Pedley, C. L. Stone, and G. L. Hartman. 2007. First Report of Soybean Rust Caused by Phakopsora pachyrhizi in Ghana. Plant Disease 91(8): 1057-1057.

Bergamin Filho, A. 1995. Curvas de progresso da doença. Em: Bergamin Filho, A., H. Kimati e L. Amorim. (Eds.) Manual de Fitopatologia: Princípios e conceitos. São Paulo, Ceres. Vol. 1.

Bergamin Filho, A., e L. Amorim. 1996. Doenças de Plantas Tropicais: Epidemiologia e Controle Econômico. São Paulo, Ceres.

Blum, M. M. C., E. M. Reis, e C. A. Forcelini, C. A. 2004. Progresso da ferrugem da soja. Fitopatologia
Brasileira 29 (Suplemento): S248 (Resumo).

Board, J. E., A. T. Wier, and D. J. Boethel. 1994. Soybean yield reductions caused by defoliation during mid to late seed filling. Agron. J. 86:1074-1079.

Bonde, M. R., J. S. Melching and K. R. Bromfield. 1976. Histology of the suscept-pathogen relationship between Glycine max and Phakopsora pachyrhizi the cause of soybean rust. Phytopathology 66:1290-1294.

Bonde, M. R., S. E. Nester, C. N. Autin, C. L. Stone, R. D. Frederick, G. L. Hartman, and M. R. Miles. 2006. Evaluation of virulence of Phakopsora pachyrhizi and P. meibomiae isolates. Plant Disease 90(6):708-716.

Bromfield, K. R. 1984. Soybean Rust. Monograph No. 11. St. Paul, American Phytopathological Society.

Bromfield, K. R., and E. E. Hartwig. 1980. Resistance to soybean rust and mode of inheritance. Crop Science 20:254-255.

Cárcamo-Rodríguez, A., J, Aguilar-Ríos, and J. R. Hernández. 2006. First Report of Asian Soybean Rust Caused by Phakopsora pachyrhizi from Mexico. Plant Disease 90(9):1260-1260.

Carlini, R. C., M. M. Muliterno, F. R. Garcés, e E. M. Reis.2009. Efeito da concentração de folhas de soja em substratos para a germinação e crescimento do tubo germinativo de Phakopsora pachyrhizi. Tropical Plant Pathology 34 (Suplemento): S117 (Resumo).

Carvalho Jr., A. A., e M. B. A. Figuereido. 2000. A verdadeira identidade da ferrugem da soja no Brasil. Summa Fitopatológica 26:197-200.

CABI (Centre for Agricultural Bioscience International). 2001. Phakopsora pachyrhizi. From Crop Protection Compendium, a CD-ROM available from CAB International, Wallinford, Oxon OX10 8DE.E-mail: cabi@cabi.org

Cheng, Y. W., and K. L. Chan. 1968. The breeding of rust resistant soybean Tainung 3. J. Taiwan Agr. Res. 17:30-34.

CONAB (Companhia Nacional de Abastecimento BR). 2009. Acompanhamento da safra brasileira 2008-2009 - Intenção de plantio, primeiro levantamento. Out. 2009. (em línea). Consultado 14 Out. 2009. Disponível em http://www.conab. gov.br/conabweb/down load/safra/1graos_09.10. pdf

Costamilan, L. M., P. F. Bertagnolli, e J. T. Yorinori. 2002. Perda de rendimento de grãos de soja causada por ferrugem asiática (Phakopsora pachyrhizi). Fitopatologia Brasileira 27 (Suplemento): S100 (Resumo).

Cunha, J. P. A. R., E. F. Reis, e R. O. Santos. 2006. Controle químico da ferrugem asiática da soja em 
função de ponta de pulverização e de volume de calda. Ciência Rural 36(5):1360-1366.

Del Ponte, E. M., C. V. Godoy, X. Li, and X. B. Yang. 2006. Predicting severity of Asian soybean rust epidemics with empirical rainfall models. Phytopathology 96:797-803.

Deuner, C., F. Nicolini, e R. C. Carlini. 2009. Histórico de evolução ao dos critérios de aplicação de fungicidas usados na cultura da soja, no Brasil. Em: Reis, E. M. (Org.). Critérios Indicadores do Momento para Aplicação de Fungicidas visando ao Controle de Doenças em Soja e Trigo. Passo Fundo, Aldeia Norte. p. 27-30.

Deslandes J. A. 1979. Ferrugem da soja e de outras leguminosas causadas por Phakopsora pachyrhizi no Estado de Minas Gerais, Fitopatologia Brasileira 4:337-339.

Díaz, H., I. Busto, O. Velázques, M. Fernández, J. González, y J. Ortega. 1992. El cultivo de la soya para granos y forrajes. Costa Rica, CIDA. (Boletín Técnico).

Dufresne, L. A., G. A. Bean, M. R. Bonde, and R. W. Goth. 1987. Effects of temperature and light intensity on telia development by Puerto Rico and Taiwan isolates of Phakopsora pachyrhizi, the soybean rust fungus. Plant Disease 71(7):629-631.

Du Preez, E. D., N. C. Van Rij, K. J. Lawrance, M. R. Miles, and R. D. Frederick. 2005. First report of soybean rust caused by Phakopsora pachyrhizi on dry beans in South Africa. Plant Disease 89:206.

Ferreira, M. C. 2009. Aplicações de fungicida para o controle da ferrugem asiática da soja e interações com diferentes arranjos espaciais da cultura. Dissertação de Mestrado em Agronomia. Fitopatologia. Universidade de Passo Fundo, Passo Fundo.

FUNDAÇÃO DE APOIO A PESQUISA AGROPECUÁRIA DE MATO GROSSO - FUNDAÇÃO MT. Cultivares de sojas convencionais. (em línea). Consultado 15 dezembro 2009. Disponível em http://www. fundacaomt.com.br/soja/

Galloti, G. J. M., A. A. Balbinot Jr., e R. L. Backes. 2006. Efeito da época de semeadura e da aplicação de fungicidas no progresso da ferrugem asiática, oídio e doenças de final de ciclo na cultura da soja. Ciências Agroveterinarias 4(2): 87:93.

Garcés, F. R. 2010. Efeito de programas de aplicação de fungicidas no progresso da ferrugem, no seu controle e na área foliar da soja. Dissertação de Mestrado em Agronomia/Fitopatologia. Universidade de Passo Fundo, Passo Fundo. 100 p.

Garcés, F. R., E. M. Reis, C. De. A. Cardoso, e C. A.
Forcelini. 2010a. Umbral numérico de infección de Phakopsora pachyrhizi en el cultivo de soya. Tropical Plant Pathology 35 (Suplemento): S168 (Resumo).

Garcés, F. R., E. M. Reis, E. Deuner, F. Nicolini, R. B. Tonin, e A. Avozani. 2010b. Severidad de Phakopsora pachyrhizi en el cultivo de soya en condiciones de invernadero. Tropical Plant Pathology 35 (Suplemento): S169 (Resumo).

Garcia, A., E. S. Calvo, R. A. Souza de Kiihl. A. Harada, D. M. Hiromoto, and R. G. E. Vieira. 2008. Molecular mapping of soybean rust (Phakopsora pachyrhizi) resistance genes: discovery of a novel locus and alleles. Theor. Appl. Genet. 117: 545553.

Gastaldi, L. F. 2005. Eficiência de fungicidas e efeito do ambiente na severidade da ferrugem asiática causada por Phakopsora pachyrhizi em soja. Dissertação de Mestrado em Agronomia. Universidade Estadual de Londrina, Londrina.

Godoy, C. V., e M. G. Canteri. 2004. Efeito protetor, curativo e erradicante de fungicidas no controle da ferrugem da soja causada por Phakopsora pachyrhizi, em casa de vegetação. Fitopatologia Brasileira 29: 97-101.

Godoy, C. V., C. B. Pimenta, D. S. Miguel-Wruck, E. U. Ramos Jr., F. V. Siqueri, H. R. Feksa, I. Dos Santos, I. O. N. LOPES, J. Nunes Jr., M. A. Ito, M. M. Iamamoto, M. F. Ito, M. C. Meyer, M. Dias, M. C. Martins, N. S. Almeida, N. S. Andrade, P. J. M. Andrade, P. I. M. Souza, R. S. Balardin, R. Barros, S. A. Silva, S. H. Furlan, e W. L. Gavassoni. 2007. Eficiência de fungicidas para controle da ferrugem asiática da soja, Phakopsora pachyrhizi, na safra 2006/07. Resultados sumarizados dos ensaios em rede. Londrina, EMBRAPA-Soja. (Circular Técnica, 42).

Godoy, C. V., A. M. Flausino, L. C. M. Santos, e E. M. Del Ponte. 2009. Eficiência do controle da ferrugem asiática da soja em função do momento de aplicação sob condições de epidemia em Londrina, PR. Tropical Plant Pathology 34: 56-61.

Hartwig, E. E. 1986. Identification of a fourth major gene conferring resistance to soybean rust. Crop Science 26: 1135-1136.

Hartwig, E. E., and K. R. Bromfield. 1983. Relationships among three genes conferring specific resistance to rust in soybeans. Crop Science 23: 237-239.

Hartman, G. L., and J. S. Haudenshield. 2009. Movement of Phakopsora pachyrhizi (soybean rust) spores by non-conventional means. European Journal Plant Pathology 123: 225-228.

Hartman, G. L., J. B. Sinclair, and J. C. Rupe. 1999. Compendium of Soybean Diseases (4ta Ed.). APS 
Press, Minnesota.

Hartman, G. L., T. C. Wang, and A. T. Tschanz. 1991. Soybean rust development and the quantitative relationship between rust severity and soybean yield. Plant Disease 75: 596-600.

Hennen, J., and F. Reid. 2002. NPAG Data: Phakopsora Pachyrhizi Australasian Soybean Rust. Draft December 9.

Hennings, V. P. 1903. [A few new Japanese Uredinaceae]. Hedwigia 42: S107-108.

Henning, A. A., e C. V. Godoy. 2006. Situação da ferrugem da soja no Brasil e no mundo. Em: Zambolim, L. (Org.). Ferrugem Asiática da Soja. Suprema Gráfica e Editora, Visconde do Rio Branco. p. 1-14.

Hidayat, O. O., and S. Somaatmadja. 1977. Screening of soybean breeding lines for resistance to soybean rust (Phakopsora pachyrhizi Sydow). Soybean Rust News 1: 9-22.

Isard, S. A., N. S. Dufault, M. R. Miles, G. L. Hartman, J. M. Russo, E. D. De Wolf, and W. Morel. 2006. The effect of solar irradiance on the mortality of Phakopsora pachyrhizi urediniospores. Plant Disease 90: 941-945.

INEC, MAG, SICA. 2002. III CENSO NACIONAL AGROPECUARIO. Resultados Nacionales y Provinciales. Instituto Nacional y Estadística del Ecuador-INEC, Ministerio de Agricultura y Ganadería-MAG, Servicio de Servicio y Censo Agropecuario-SICA. Quito, Ecuador.

Ivancovich, A. 2005. Soybean rust in Argentina. Plant Disease 89(6): 667-668.

Jesus Jr. W. C., E. A. Pozza, F. X. R. Vale, e G. MoraAguilera. 2004. Análise Temporal de Epidemias. Em: Vale, F. X. R., W. C. Jesus Jr., e L. Zambolim. (Eds.). Epidemiologia Aplicada ao Manejo de Doenças de Plantas. Perffil Editora, Viçosa.

Kawuki, R. S., E. Adipala, and P. Tukamuhabwa. 2003. Yield loss associated with soya bean rust (Phakopsora pachyrhizi Syd.) in Uganda, Journal of Phytopathology 151: 7-12.

Keogh, R. C. 1974. Studies on Phakopsora pachyrhizi Syd.: the causal agent of soybean rust. 1974. Dissertation of Master to Agronomy. University of Sydney, Sydney.

Killgore, E., and R. Heu. 1994. First report of soybean rust in Hawaii. Plant Disease 78: 1216.

Kim, K. S., T. C. Wang, and X. B. Yang. 2005. Simulation of apparent infection rate to predict severity of soybean rust using a fuzzy logic system. Phytopathology 95: 1122-1131.

Koch, E., F. Ebrahin-Nesbat, and H. H. Hoppe. 1983. Light and electron microscopic studies on the development of soybean rust (Phakopsora pachyrhizi Syd.) in susceptible soybean leaves. Journal of Phytopathology 106: 302-320.

Kochman, J. K. 1977. Soybean rust in Australia. In: Ford, R. E., and J. B. Sinclair. (Eds.). Rust of soybean - The problem and research needs. $\mathrm{N}^{\circ}$ 12. University of Illinois, Urbana.

Kochman, J. K. 1979. The effect of temperature on development of soybean rust (Phakopsora pachyrhiri). Australian Journal of Agricultural Research 30: 273-277.

Koga, L. J., M. C. Canteri, E. S. Calvo, J. R. Unfried, A. Garcia, A. Harada, and R. A. S. Kiihl. 2008. Análise multivariada dos componentes da resistência à ferrugem-asiática em genótipos de soja. Pesquisa Agropecuária Brasileira 43(10): 1277-1286.

Levy, C. 2005. Epidemiology and chemical control of soybean rust in Southern Africa. Plant Disease 89: 669-674.

Littlefield, L. J., and W. K. Schimming. 1989. Size and shape of Urediniospores as influenced by ambient relative humidity. Mycotaxon 36: 187-204.

Lynch, T. N., J. J. Marois, D. L. Wright, P. F. Harmon, C. L. Harmon, M. R. Miles, and G. L. Hartman. 2006. First report of soybean rust caused by Phakopsora pachyrhizi on Phaseolus spp. in the United States. Plant Disease 90: 970.

Maciel, P, H, F, Z, A., C. A. Viecelli, F. Mioranza, e T. Dalla Nora. 2009. Controle in vitro de Phakopsora pachyrhizi por extratos de Cyperus rotundus. Tropical Tropical Plant Pathology 34 (Suplemento): S32 (Resumo).

MAPA. 2009. Ministério da Agricultura, Pecuária e Abastecimento. (em línea). Consultado 21 agosto 2009. Disponível em: http://extranet.agricultura. gov.br/sislegis-consulta/consultarLegislacao. do? Operação $=$ visualizareid $=16534$.

Marchetti, M. A., J. S. Melching, and K. R. Bromfield. 1976. The effects of temperature and dew period on germination and infection by uredospores of Phakopsora pachyrhizi. Phytopathology 66: 461463.

Maude, R. B. 1996. Seedborne disease and their control. Principles and practice. CAB International, Oxon.

Mawuena, G. 1982. Preliminary observations on soybean rust incidence in Togo. Soybean Rust Newsletter 5: 20-21.

Mclean, R. J., and D. E. Byth. 1980. Inheritance of resistance to rust (Phakopsora pachyrhizi) in soybean. Aust. J. Agric. Res. 31: 951-956.

Medice, R. 2007. Produtos alternativos no manejo da ferrugem asiática (Phakopsora pachyrhizi) da soja. Dissertação de Mestrado em Agronomia/ Fitopatologia. Universidade Federal de Lavras, 
Lavras.

Melching, J. S., W. M. Dowler, D. L. Koogle, and M. H. Royer. 1989. Effects of duration, frequency, and temperature of leaf wetness periods on soybean rust. Plant Disease 73:117-122.

Misman, R., and E. S. A. Purwati. 1985. A study on host plant types of soybean rust fungi (Phakopsora pachyrhizi Syd.) on various types of legumes. Bull. Ilmaih Unsoed 11:68-82.

Miles, M. R., R. D. Frederick, and G. L. Hartman. 2006. Evaluation of soybean germplasm for resistance to Phakopsora pachyrhizi. Plant Management Network, 2006. (en línea). Consulting 12 July 2009. Publication in: http:// www.plantmanagementnetwork.org/pub/php/ research/2006/germplasm/

Morel, W., and J. T. Yorinori. 2002. Situación de la roya de la soja en el Paraguay. Centro Regional de Investigación Agricola-CRIA, Capitan Miranda. (Boletín Divulgativo, 44). 4 p.

Navarini, L., L. J. Dallagnol, R. S. Balardin, M. T. Moreira, R. C. Meneghetti, e M. G. Madolosso. 2007. Controle químico da ferrugem asiática (Phakopsora pachyrhizi Sydow) na cultura da soja. Summa Phytopathologica 33(2):182-186.

Navarro, J. C., R. Nakasato, C. M. Utiamada, and J. T. Yorinori. 2004. First report f Asian soybean rust in Bolivia. World Soybean Research Conference, VII International Soybean Processing and Utilization Conference, IV Brazilian Soybean Congress. (Supplement): 85- 86 (Abstract).

Nicolini, F., E. M. Reis, S. M. Zoldan, A. L. D. Danelli, M. Zanatta, A. Avozani, R. B. Tonin, e F. R. Garcés. 2010a. Efeito de temperaturas na germinação de uredosporos de Phakopsora pachyrhizi. Tropical Plant Pathology 35 (Suplemento): S143 (Resumo).

Nicolini, F., E. M. Reis, S. M. Zoldan, A. L. D. Danelli, M. Zanatta, A. Avozani, R. B. Tonin, e F. R. Garcés, 2010b. Efeito da radiação solar na germinação de uredosporos da ferrugem da soja. Tropical Plant Pathology 35 (Suplemento): S143 (Resumo).

Ono, Y., P. Buritica, and J. F. Hennen. 1992. Delimitation of Phakopsora, Physopella and Cerotelium and their species on Leguminosae. Mycol Res. 96(10):825-850.

Pan, Z., X. B. Yang, S. Pivonia, L. Xue, R. Pasken, and J. Roads. 2006. Long-term prediction of soybean rust entry into the continental United States. Plant Disease 90:840-846.

Park, S., Z. Y. Chen, A. K. Chanda, R. W. Schneider, and C. A. Hollier. 2008. Viability of Phakopsora pachyrhizi urediniospores under simulated Southern Louisiana winter temperature conditions. Plant Disease 92(10):1456-1462.
Pham, T. A., M. R. Miles, R. D. Frederick, C. B. Hil,1 and G. L. Hartman. 2009. Differential response of resistant soybean genotypes to ten isolates of Phakopsora pachyrhizi. Plant Disease 93:224228.

Pivonia, S., and X. B. Yang. 2006. Relating epidemic progress from a general disease model to seasonal appearance time of rusts in the United States: Implications for soybean rust. Phytopathology 96:400-407.

Poolpol, U., and U. Pupipat. 1985. Morphology, development, induced teliospore formation and host range of Phakopsora pachyrhizi Syd. Soybean Rust Newsletter 7:26-27.

Poonpolgul, S., and P. Surin. 1980. Study of host range of soybean rust fungus in Thailand. Soybean Rust Newsletter 3:30-31.

Pretorius, Z. A., F. J. Kloppers, and R. D. Frederick. 2001. First report of soybean rust in South Africa. Plant Disease 85(12): 1288.

Ramos, J. P., L. S. Domingues, D. Debona, D. D. Favena, A. Manfio, G. Lenz, e R. S. Balardin. 2009. Arranjo populacional no manejo da ferrugem asiática da soja. Tropical Plant Pathology 34 (Suplemento): S178 (Resumo).

Reis, E. M., R. T. Casa, e C. Michel. 2002. Ocorrência de epidemia da ferrugem da soja no Rio Grande do Sul na safra 2001/2002. Fitopatologia Brasileira 27 (Suplemento): S198 (Resumo).

Reis, E. M., e A. C. R. Bresolin. 2004. Ferrugem da soja: revisão e aspectos técnicos. Em: Reis, E. M. (Ed.). Doenças na Cultura da Soja. Aldeia Norte, Passo Fundo. p. 55-70.

Reis, E. M., A. F. Sartori, e R. K. Camara. 2004. Modelo climático para a previsão da ferrugem da soja. Summa Phytopathologica 30:290-292.

Reis, E. M., O. Scheer, e J. Rovedor. 2005. Kudzú (Pueraria lobata) hospedeiro secundário de Phakopsora pachyrhiz, no Brasil. Fitopatologia Brasileira 30 (Suplemento): S130 (Resumo).

Reis, E. M., A. C. R. Bresolin, e M. Carmona. 2006a. Doenças da soja I: Ferrugem asiática. Universidade de Passo Fundo, Passo Fundo.

Reis, E M., M. Zanatta, E. N. Moreira, R. Bogorni, L. Remor, e D. 2006b. A. Curva de progresso da ferrugem da soja em Passo Fundo-RS. Fitopatologia Brasileira 31 (Suplemento): S139 (Resumo).

Rytter, J. L., W. M. Dowler, and K. R. Bromfield. 1984. Additional alternative hosts of Phakopsora pachyrhizi, causal agent of soybean rust. Plant Disease 68:818-819.

Rossi, R. L. 2003. First report of Phakopsora pachyrhizi, the causal organism of Soybean Rust in the 
province of Misiones, Argentina. Plant Disease $87: 102$.

Shuxian, L. I. 2010. Identification of New Sources of Resistence to Soybean Rust. In: Gisi, U., L. L. Chet, and M. L. Gullino. (Eds.) Recent Developments in Management of Plant Diseases. Springer, Netherlands. p. 357-373.

Sato, T., and S. Sato. 1982. Infective ability of soybean rust to several leguminous plants. Soybean Rust Newsletter 5:22-26.

Schneider, R. W., C. A. Hollier, and H. K. Whitam. 2005. First report of soybean rust caused by Phakopsora pachyrhizi in the continental United States. Plant Disease 89:774.

Scherm, H., R. S. C. Christiano, P. D. Esker, E. M. Del Ponte, e C. V. Godoy. 2009. Quantitative review of fungicide efficacy trials for managing soybean rust in Brazil. Crop Protection 28:774-782.

Sinclair, J. B., and P. A. Backman. 1993. Compendium of Soybean Diseases (3th Ed.). American Phytopathological Society, St. Paul.

Sinclair, J. B. and G. L. Hartman. 1995. Soybean Rust Workshop. Illinois Proceedings, Urbana.

Slaminko, T. L., M. R. Miles, R. D. Frederick, M. R. Bonde, and G. L. Hartman. 2008. New legume hosts of Phakopsora pachyrhizi based on greenhouse evaluations. Plant Disease 92(5):767771.

Sotomayor-Herrera, I. 2005. La roya de la soya, estratégias de manejo. INIAP-Pichilinge, Quevedo. (Boletín divulgativo, 330). 4 p.

Sousa, P. F. C., E. Alves, e H. Castro. 2006. A. Influência da temperatura no desenvolvimento de teliósporos de Phakopsora pachyrhizi em folíolos de soja. Summa Phytopathologica 32(3):227-231.

Souza J., y A. N. Formento, A. N., 2008. Progreso de la roya asiática de la soja (Phakopsora pachyrhizi) en Entre Ríos. En: INTA. (Org.). Actualización Técnica Cosecha Gruesa. INTA, Entre Ríos. p. 23-27.

Stavely, J. R., J. L. Rytter, and M. H. Royer. 1985. Virulence of the soybean rust pathogen, Phakopsora pachyrhizi on Phaseolus vulgaris cultivars. Annu. Rep. Bean Improv. Coop. 28:3536.

Stewart, S., E. A. Guillin, and L. Díaz. 2005. First Report of Soybean Rust Caused by Phakopsora pachyrhizi in Uruguay. Plant Disease 89(8):909.

Tsukahara, R. Y., M. Hikishima, and M. G. Canteri. 2008. Relações entre o clima e o progresso da ferrugem asiática (Phakopsora pachyrhizi) em duas micro-regiões do Estado do Paraná. Semina: Ciências Agrárias 29(1):47-52.

Vakili, N. G. and K. R. Bromfield. 1976. Phakopsora rust on soybean and other legumes in Puerto Rico. Plant Disease 60:995-999.

Van de Mortel, M., K. T. Schneider, T. Bancroft, D. Nettleton, R. D. Frederick, T. J. Baum, and S. A. Whitham. 2007. Gene expression in a soybean cultivar containing the Rpp3 gene for resistance to Phakopsora pachyrhizi. Phytopathology 97 (Supplement): S117 (Abstract).

Van der Plank, J. E. 1963. Plant Diseases: Epidemics and Control. Academic Press, New York e London.

Van der Plank, J. E. 1968. Disease Resistance in Plants (1th Ed.). Academic Press, New York e London.

Viero, V. C. 2008. Epidemiologia comparativa entre a ferrugem asiática da soja e a ferrugem da folha do trigo. Dissertação de Mestrado em Agronomia/ Fitopatologia. Universidade de Passo Fundo, Passo Fundo.

Yamanaka, N., Yamaoka, Y., Kato, M., Lemos, N. G., Passianotto, A. L. L., Santos, J. V. M., Benitez, E. R., Abdelnoor, R. V., Soares, R. M., Suenaga, K. 2010. Development of classification criteria for resistance to soybean rust and differences in virulence among Japanese and Brazilian rust populations. Tropical Plant Pathology 35(3):153162.

Yang, X. B., W. M. Dowler, and A. T. Tschanz. 1991a. A simulation model for assessing soybean rust epidemics. Journal of Phytopathology 133:187200.

Yang, X. B., A. T. Tschantz, W. M. Dowler, and T. C. Wang. 1991b. Development of yield models in relation to reduction of components of soybean infected with Phakopsora pachyrhizi. Phytopathology 81:1420-1426.

Yang, X. B., W. M. Dowler, A. T. Tschanz, and T. C. Wang. 1992. Comparing the effects of rust on plot yield, plant yield, yield components, and vegetative parts of soybean. Journal of Phytopathology 136: 46-56.

Yáñez-Morales, MA. de Jesús., I. Martínez-Alanis, M. J. Soto Rocha, D. K. Malvick, J. E. Kurle, C. M. Floyd, and S. V. Krupa. 2009. Soybean Rust Caused by Phakopsora pachyrhizi detected in the State of Campeche on the Yucatan Peninsula, Mexico. Plant Disease 93(8):847.

Yeh, C. C., A. T. Tschanz, and J. B. Sinclair. 1981. Induced teliospore formation by Phakopsora pachyrhizi on soybeans and other hosts. Phytopathology 71:1111-1112.

Yorinori, J. T. 1997. Controle integrado de doenças de soja. Em: EMBRAPA. Resultados de pesquisa de soja, 1997. EMBRAPA - CNPSo, Londrina. p. 83.

Yorinori, J. T., P. W. Morel, R. D. Frederick, L. M. Costamilian, and P. F. Bertagnolli. 2002a. 
Epidemia de ferrugem da soja (Phakopsora pachyrhizi) no Brasil e no Paraguai, em 2001 e 2002. Fitopatologia Brasileira 27 (Suplemento): S178 (Resumo).

Yorinori, J. T., W. M. Paiva, R. D. Frederick, and P. F. T. Fernandez. 2002b. Ferrugem da soja (Phakopsora pachyrhizi) no Brasil e no Paraguai, nas safras 2001/01 e 2001/02. Anais Congresso Brasileiro de Soja 2002:94 (Resumo).

Yorinori, J. T. 2004. Ferrugem da soja: ocorrência no Brasil e estratégias de manejo. Em: Reis, E. M. (Ed.). Doenças na Cultura da Soja. Aldeia Norte, Passo Fundo. p. 77-84.

Zambenedetti, E. B. 2005. Preservação de Phakopsora pachyrhizi Sydow e Sydow e aspectos epidemiológicos e ultra-estruturais da sua interação com a soja (Glycine $\max$ (L.) Merril). Dissertação de Mestrado em Agronomia/ Fitopatologia. Universidade Federal de Lavras, Lavras.
Zambenedetti, E. B., E. Alves, e D. V. 2007a. Araújo. Eventos dos processos de pré-penetração, penetração e colonização de Phakopsora pachyrhizi em folíolos de soja. Fitopatologia Brasileira 32:156-160.

Zambenedetti, E. B., E. Alves, E. A. Pozza, e D. V. Araújo, e C. V. Godoy. 2007b. Avaliação de parâmetros monocíclicos e da intensidade da ferrugem asiática (Phakopsora pachyrhizi) em diferentes genótipos de soja e posições de copa. Summa Phytopathologica 33(2):178-181.

Zambolim, L. 2006. Manejo Integrado da Ferrugem Asiática da Soja. Em: Zambolim, L. (Org.). Ferrugem Asiática da Soja. Suprema Gráfica e Editora, Visconde do Rio Branco. p. 73-98.

Zambolim, L., W. S. Venâncio e S. H. Furlan de Oliveira. 2007. Manejo de Resistência de Fungos a Fungicidas. Suprema Gráfica e Editora, Visconde do Rio Branco. 